\title{
4
}

\section{Industrial Assistance Systems to Enhance Human-Machine Interaction and Operator's Capabilities in Assembly}

\author{
Benedikt G. Mark, Erwin Rauch, and Dominik T. Matt
}

\subsection{Introduction}

This chapter discusses industrial assistance systems, which can be used to enhance the operator's capabilities and the human-machine interaction (HMI) during production processes. It presents solutions for HMI and automation, and delivers insights into different possibilities

B. G. Mark (区) · E. Rauch · D. T. Matt Industrial Engineering and Automation (IEA), Faculty of Science and Technology, Free University of Bozen-Bolzano, Piazza Università 1, 39100 Bolzano, Italy

e-mail: benediktgregor.mark@unibz.it

E. Rauch

e-mail: erwin.rauch@unibz.it

D. T. Matt

e-mail: dominik.matt@unibz.it; dominik.matt@fraunhofer.it

D. T. Matt

Innovation Engineering Center (IEC), Fraunhofer Research Italia S.C.a.R.L, Via A.-Volta 13a, 39100 Bolzano, Italy 
to enhance the various types of operators' skills in industrial assembly. In the course of the fourth industrial revolution, also called Industry 4.0 (I4.0), that was introduced in the year 2011 at the Hannover fair (Deutscher Bundestag 2016), the world of work is changing comprehensively. Smaller lot sizes, an increasing variability of products and increasing complexity in the modern industrial production present new challenges for operators working in manual assembly (Matt 2007, 2009; Rauch et al 2017). Industrial assistance systems help the worker during these production tasks to enhance their capabilities. The development of these systems is not only characterized by questions of the potential feasibility of new technical systems, but also by the possibilities of closer cooperation between humans and machines. Furthermore, it aims to synergize the outstanding abilities of humans with the special features of machines to bring together the best from both worlds. With the knowledge that is given in this chapter, each worker can be individually equipped with suitable supporting systems in order to be best prepared for future challenges in the daily production.

This chapter is structured as follows: It is divided into five sections. After a short introduction in the first section, Sect. 2 gives an overview of the theoretical background. In this section, industrial assistance systems are introduced in general and user groups of assistance systems are presented. Further, the importance of human-machine interaction in production is outlined and a brief analysis of the relevance of assistance systems in literature is given. Based on the three categories of aid systems (sensorial, cognitive, and physical), Sect. 3 explains and presents individual assistance systems within each category. Section 4 discusses risks, challenges, and potential in the context of industrial assistance systems. Finally, in Sect. 5, a short conclusion summarizes the main findings of this chapter. The content of this chapter should not only be of interest for researchers, but especially also for practitioners from SME companies in the field of assembly and manufacturing. 


\subsection{Theoretical Background}

\subsubsection{Industrial Assistance Systems}

The demographic development in most of the highly industrialized countries in Europe and many other emerging challenges increase the need for assistance systems (Mueller et al. 2018). Assistance or aid systems should help the operator to conduct his/her daily work appropriately. Within these systems, it can be differentiated between technological systems that support and systems that substitute humans. The following four aspects characterize a technical system that can be seen as a worker assistance system (Weidner et al. 2015):

1. The technical system supports the operator and does not replace him, 2. The technical system can always be overruled by the operator,

3. The technical system is used by the operator,

4. The technical system does not provoke any hazard for the operator.

Assistance systems can have diverse functionalities and advantages that support the operator's daily work. The following list points out the most relevant features that can be increased, decreased, and enabled by the usage of these systems (Mark et al. 2019a):

- Increase of: physical support, cognitive support, speed and productivity, quality control, comfort and convenience, ergonomics, worker capacity, worker safety, worker integration, location independence.

- Decrease of: mental stress, language barrier, search times.

- Enabling of: health control.

In the field of technological change, the range of tasks and requirements of people in manufacturing companies will change dramatically. Assistance systems are an important element on the way to the smart factory. Visualized work instructions increase the skills of the employees, the quality of the products and ultimately the productivity and competitiveness of a company (Rothenberger 2020). Nonetheless, the human being with his characteristic of complex perception, his ability to see, 
touch, grasp, and hear as well as his cognitive abilities offers suitable conditions to react flexibly and quickly to production conditions (Böhle 2005; Arnold and Furmans 2019). The frequent changes in manual work processes, which are caused by the changes on the market, on the one hand lead to more interesting and varied work content for the operator. On the other hand, the worker's requirements regarding performance, concentration, and stamina increase, which may cause a greater susceptibility to errors (Reinhart and Zäh 2014). Due to the high variance of products, a high qualification of the employees is required to ensure a consistently high quality of the manual activities (Bächler et al. 2018). This can be reached by increasing the operator's capabilities through worker assistance systems.

\subsubsection{User Groups in Production}

With the introduction of the fourth industrial revolution, the production moves towards a factory in which robots and workers interact and collaborate with each other (Gualtieri et al. 2020). In addition, employees are supported by web-based technologies and diverse assistance systems (Gorecky et al. 2014). When looking at different user groups working in nowadays production, one realizes that there are many different types of operators. Although it looks like this in reality, in most of scientific literature, only one general type of employee or worker is mentioned and most of the papers do not address different types of user groups. The term "Operator 4.0" has been introduced by Romero to describe the change of the industrial worker in production and the "operator of the future", a smart and skilled worker, who undertakes work with the help of machines and digital/technical systems (Romero et al. 2016a). The term "Operator 4.0" announces the fourth generation of worker. These four different operator generations can be seen in Fig. 4.1.

As already mentioned, in literature, only few papers address specific user groups. Mostly, in order to deduce specifications for the aid system, a primary aim is addressed, such as to support a new employee (Hallewell et al. 2018). For the help of elderly and impaired operators, "gamification" can be used. Motivation mechanics, which originally come from 


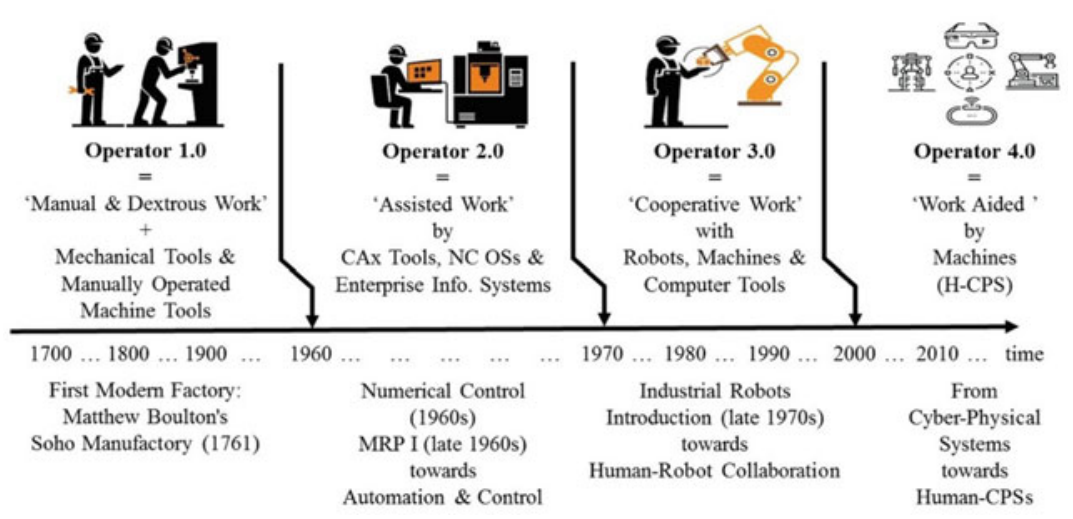

Fig. 4.1 The four operator generations (Romero et al. 2016a)

the game design, can be implemented with gamification to the industrial environment (Korn 2012; Hinrichsen et al. 2016). When looking at different types of user groups, the authors propose a distinction into nine groups (Mark et al. 2019a, 2020a). These different user groups of assistance systems in production can be seen in Table 4.1. The approach for classifying different workers with regard to their needs and limitations, due to, e.g. their origin or age, helps to adequately equip them with appropriate assistance systems.

\subsubsection{Importance of Human-Machine Interaction in Production}

HMI is nondescript and at the same time occurs rather naturally. Therefore, it is often forgotten how important a user-friendly interaction is. HMI occurs through human-machine interfaces, which can be described as the interface between machine and operator. It is the part of a machine used by people to interact and through which they can intervene. This ranges from simple everyday objects such as the steering wheel (to control a car on the street) to high-performance and complex systems (Juschkat 2019). Nonetheless, this always entails the risk that the complexity of HMI grows along with the performance and capability of industrial 
Table 4.1 User groups of industrial assistance systems (Mark et al. 2019a)

\begin{tabular}{|c|c|c|}
\hline Variable & User group & Description \\
\hline Age & Elder worker & $\begin{array}{l}\text { Worker with increasing } \\
\text { age, which might } \\
\text { have an impact on } \\
\text { the task performance }\end{array}$ \\
\hline Education & Unskilled worker & $\begin{array}{l}\text { Worker, who does not } \\
\text { have the required or } \\
\text { recommended } \\
\text { skills/education }\end{array}$ \\
\hline Experience & Unexperienced worker & $\begin{array}{l}\text { New or temporary } \\
\text { worker in the } \\
\text { company, } \\
\text { department, or the } \\
\text { specific workplace }\end{array}$ \\
\hline $\begin{array}{l}\text { Variety of work } \\
\text { content }\end{array}$ & Flexible worker & $\begin{array}{l}\text { Worker, who switches } \\
\text { often between } \\
\text { different types of } \\
\text { work (or products) } \\
\text { within a company } \\
\text { (e.g. "Jolly") }\end{array}$ \\
\hline \multirow[t]{2}{*}{$\begin{array}{l}\text { Occupational Health } \\
\text { and Safety (OHS) }\end{array}$} & Worker with safety risk & $\begin{array}{l}\text { Worker with work } \\
\text { conditions that might } \\
\text { have an impact on } \\
\text { the safety }\end{array}$ \\
\hline & Worker with health risk & $\begin{array}{l}\text { Worker with work } \\
\text { conditions that might } \\
\text { have an impact on } \\
\text { the health and } \\
\text { ergonomics }\end{array}$ \\
\hline \multirow[t]{2}{*}{ Handicap presence } & $\begin{array}{l}\text { Physically handicapped } \\
\text { worker }\end{array}$ & $\begin{array}{l}\text { Worker with physical } \\
\text { disability that might } \\
\text { have an impact on } \\
\text { the task performance }\end{array}$ \\
\hline & $\begin{array}{l}\text { Mentally handicapped } \\
\text { worker }\end{array}$ & $\begin{array}{l}\text { Worker with mental } \\
\text { disability that might } \\
\text { have an impact on } \\
\text { the task performance }\end{array}$ \\
\hline Migration & Migrant worker & $\begin{array}{l}\text { Worker who usually } \\
\text { has a different } \\
\text { background in terms } \\
\text { of culture and } \\
\text { language }\end{array}$ \\
\hline
\end{tabular}


machines. A noticeable change is the increasing technical and informative complexity and hence also the increasing specialist knowledge that the user needs to operate with an interface. It has become increasingly complex over the years, and in most of the cases, modern user interfaces can no longer be understood by non-specialists (Juschkat 2019).

The evolution of human-machine interfaces has passed many milestones over the years starting from the beginning of automation. These stages can be seen in Fig. 4.2. The fastest step could be noticed right after the first industrial revolution. In the course of the first industrial revolution, machines were brought on the market and hence in industrial production. Workers regulated machines directly through levers, cranks, or pedals. With the electricity, that was brought in the course of the second industrial revolution, employees started to control machines via switches to turn power on and off and lights for the purpose of signalization. This can be seen as the origin of modern humanmachine interfaces, the so-called HMI 0.0 (Papcun et al. 2018). In the following and in Fig. 4.2, the different evolutionary steps towards modern human-machine interfaces are shown:

- Human-Machine Interface 1.0. The first level of human-machine interfaces starts with the third industrial revolution in the 1960s in which buttons, displays, and lights were used to facilitate the work for the employees and to interact with the machines in a better way.

- Human-Machine Interface 2.0. The second level started in the 1990s and uses desktop visualization and touch panels.

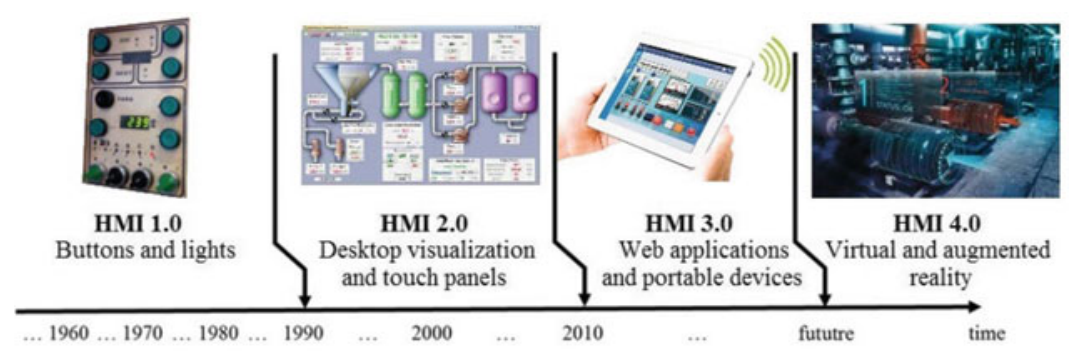

Fig. 4.2 Evolution of human-machine interfaces (Papcun et al. 2018) 
- Human-Machine Interface 3.0. The third level works with wireless visualization boards and portable devices with diverse web applications.

- Human-Machine Interface 4.0. The fourth level of human-machine interfaces uses augmented and virtual reality on mobile terminals with a camera or corresponding glasses to expand the real world with additional elements.

It was already possible in early stages to trigger any effects with devices that were placed far away by just a few hand movements. Therefore, human-machine interfaces have already made a decisive contribution to machine safety. A human-machine interface consists of four components: (i) human (operator), (ii) display, (iii) input box, and (iv) machine. The user approaches the display with the input box. The action that had been conducted in the input box triggers certain actions on the machine. The purpose of today's interfaces is to show the reaction of the machine in its essential points on the display. This gives the human operator feedback on the effect of his action on the input box and not necessarily on the machine itself (Juschkat 2019).

\subsubsection{Relevance of Assistance Systems in Literature}

For an extended literature review, the database Scopus was used. A selection of relevant keywords was established with which the search was carried out. When looking at the scientific literature about assistance systems in production, it becomes evident that the number of publications increases (see Fig. 4.4). Figure 4.4 shows the number of publications that could be identified with the scientific citation and abstract database Scopus. From the years 2003 to 2010, the number of publications is consistently low. Only in 2008, there is a small peak. From 2011, the year in which the term Industry 4.0 was introduced, the number of publications and thus the interest in this topic increased. In the year 2019, publications were double as already the year before. This confirms that there is a growing interest in technologies that help 
the operator during production tasks. A total of 171 scientific publications could be identified between the years 2003 and 2019, out of which 87.7 per cent are conference articles, 10 per cent journal articles, and 2.3 per cent book chapters (see Fig. 4.3). Figure 4.5 illustrates the countries from which the research publications originate. Germany, the country in which the term "Industry 4.0" was born, is leading and claims 66.1 per cent of the publications, followed by Austria with 7.0 per cent and the USA with 5.3 per cent.

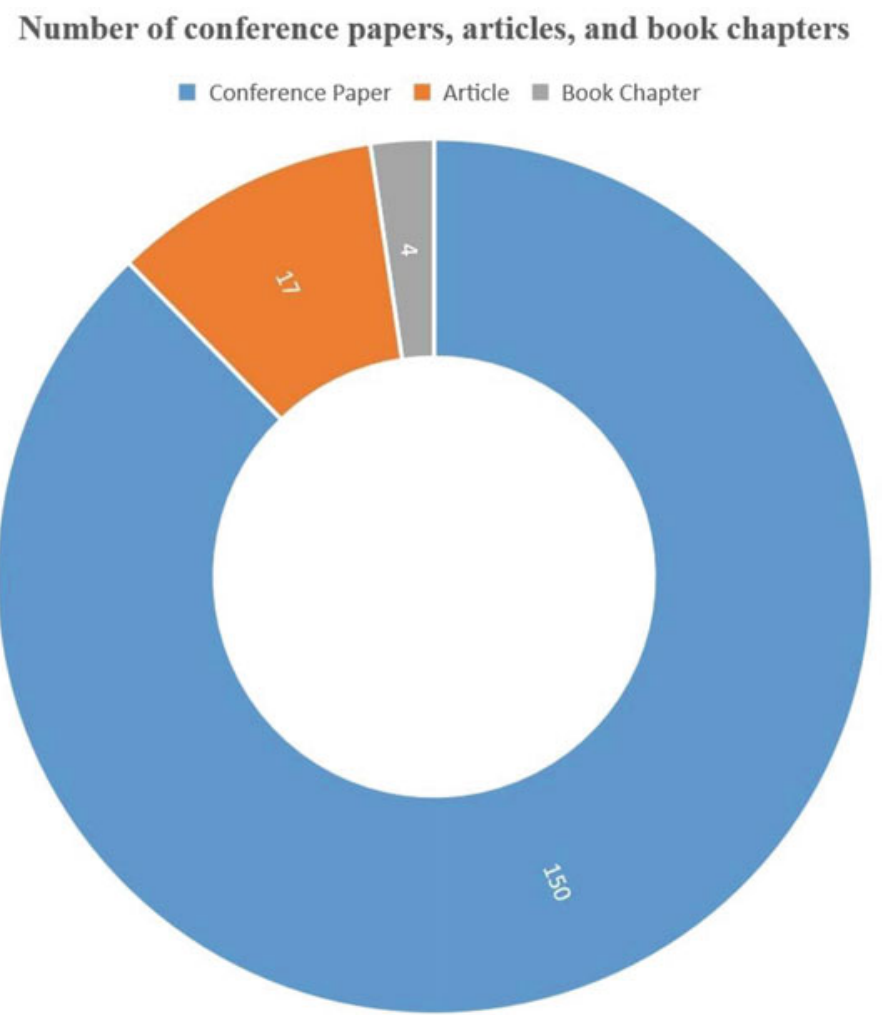

Fig. 4.3 Number of publications per year 


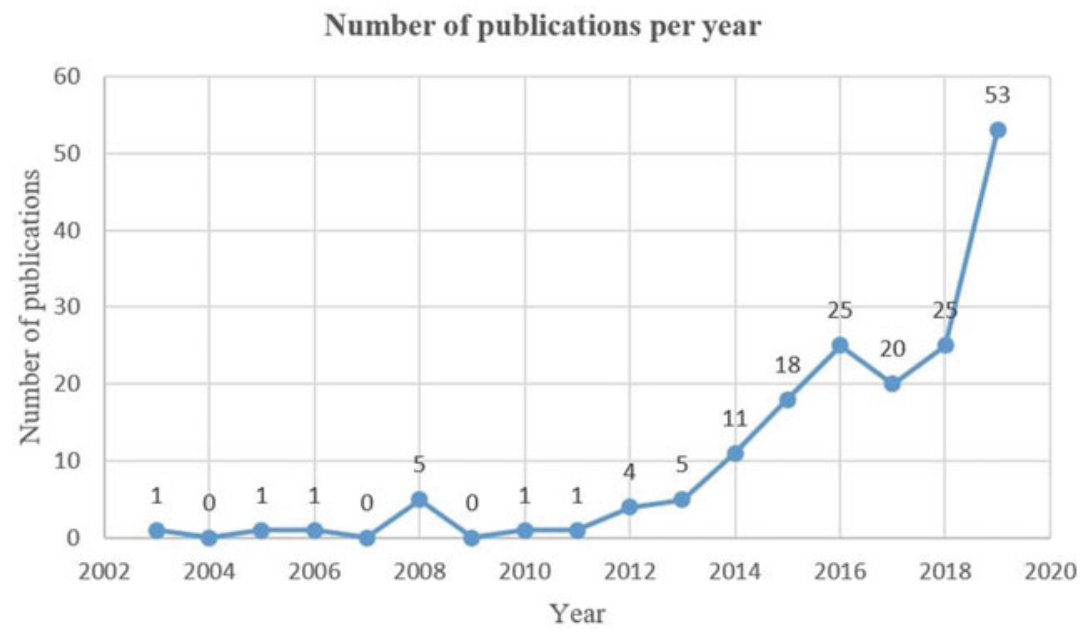

Fig. 4.4 Number of conference papers, articles, and book chapters

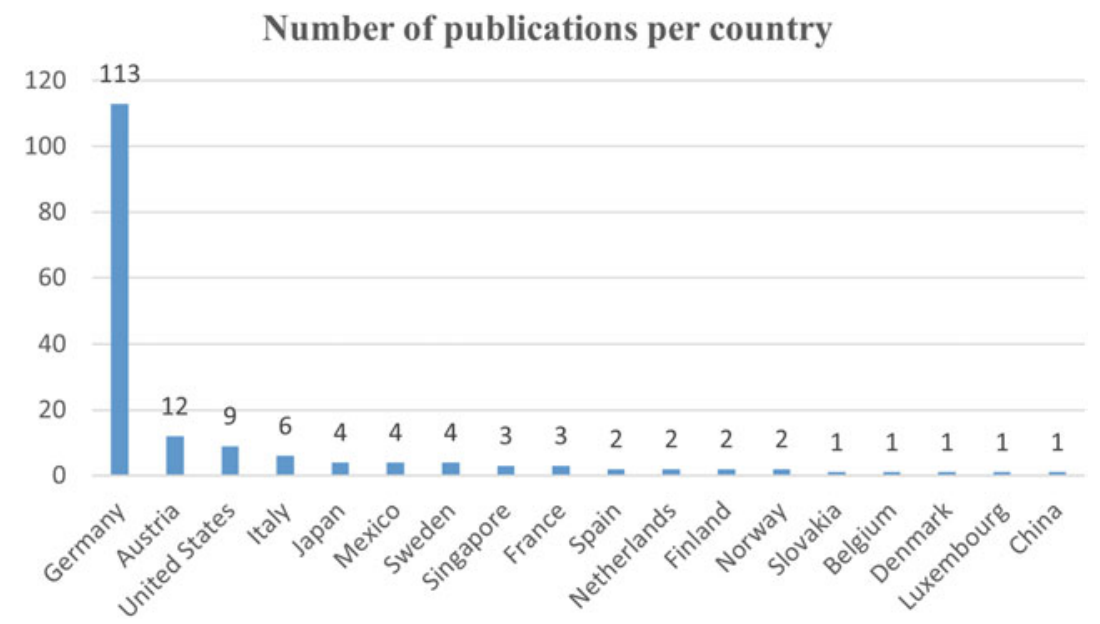

Fig. 4.5 Number of publications per country 


\subsection{Overview of Industrial Assistance Systems in Production}

After the introduction and the presentation of the theoretical background in industrial assistance systems, we want to give a clear overview of categories of such aid systems and a presentation of the different systems as well as exemplary applications in industrial assembly. To present the three main categories of industrial assistance systems, we need to introduce the term "capability". The definition of the capability is the "measure of the ability of an entity (e.g. department organisation, person, system) to achieve its objectives, especially in relation to its overall mission" (Business Dictionary 2016). This means, related to humans/workers, that they have the ability and assets to apply the capabilities for a certain objective (Romero et al. 2016a). Based on this concept of capabilities, in literature, industrial assistance systems are subdivided into three categories: (i) sensorial, (ii) cognitive, and (iii) physical assistance systems based on their ability to extend the capabilities of a worker (see Fig. 4.6).

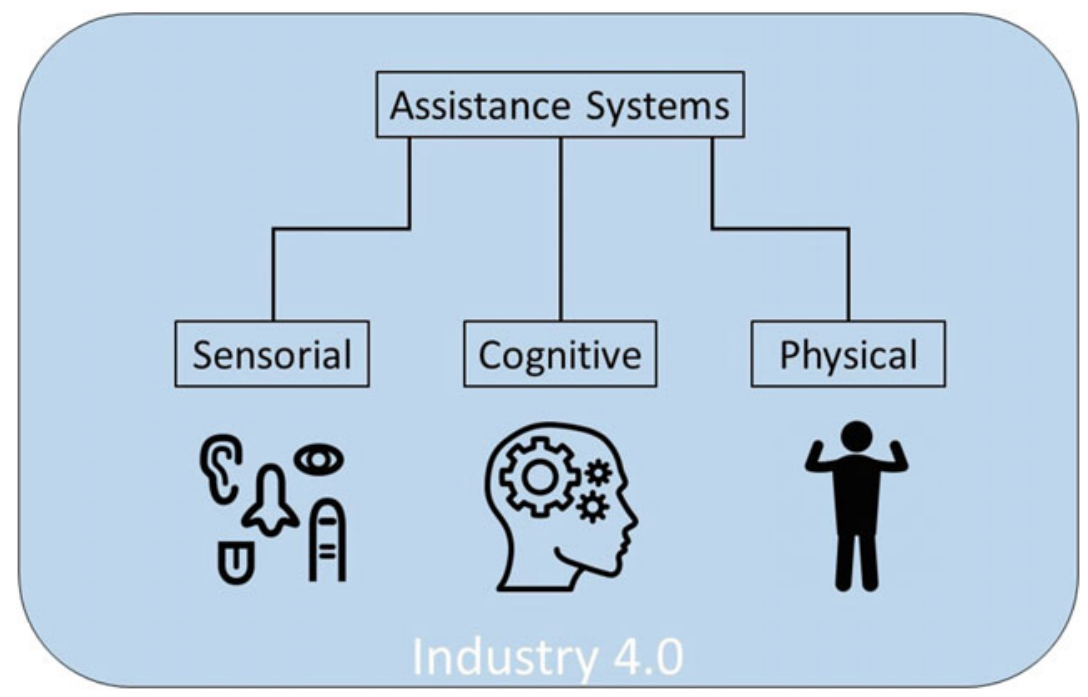

Fig. 4.6 Categorization of industrial assistance systems 
- Cognitive Assistance Systems. Cognitive assistance systems provide information and support learning in real time. They help the user with information processing and with the execution of his/her work. Examples of cognitive assistance system are smartphones, virtual reality, augmented reality, tablets, smartwatches, and wearables. Cognitively supportive assistance systems can provide information, generate guidelines for actions, steps, and processes, and provide rated feedback. Furthermore, they can collect data for use, e.g. work progress, working speed, and times (Zittlau 2015a).

- Physical Assistance Systems. Physical assistance systems can support the physical performance of an operator. Often, exoskeletons are mentioned in this context. They can be worn as "robot suits" or support individual limbs, such as the arms or legs. Exoskeletons especially help with carrying, lifting, walking, and special systems even sitting without a chair. The aim of physical assistance systems is to combine the advantages of humans (e.g. flexibility) and technology (e.g. endurance), hence facilitating movements of the user and preventing health risks. It is important to adapt the assistance systems to the individual operator needs and the corresponding situation. Wearing physically assistance systems must not be a burden or create additional risks (Zittlau 2015b).

- Sensorial Assistance Systems. Sensing can be divided into two different parts: (i) the ability to collect information from the surroundings by using the senses (e.g. sound and touch) and (ii) the ability to notice it selectively (Romero et al. 2016b). Many sensorial assistance systems are already installed in factories, such as warning lights or audible signals. The goal is to increase the hazard awareness and attention and to be easily understood also from far away (Layne 2019).

Table 4.2 provides an overview of assistance systems categorized in sensorial, cognitive, and physical aid systems. 
Table 4.2 Overview of industrial assistance systems in production

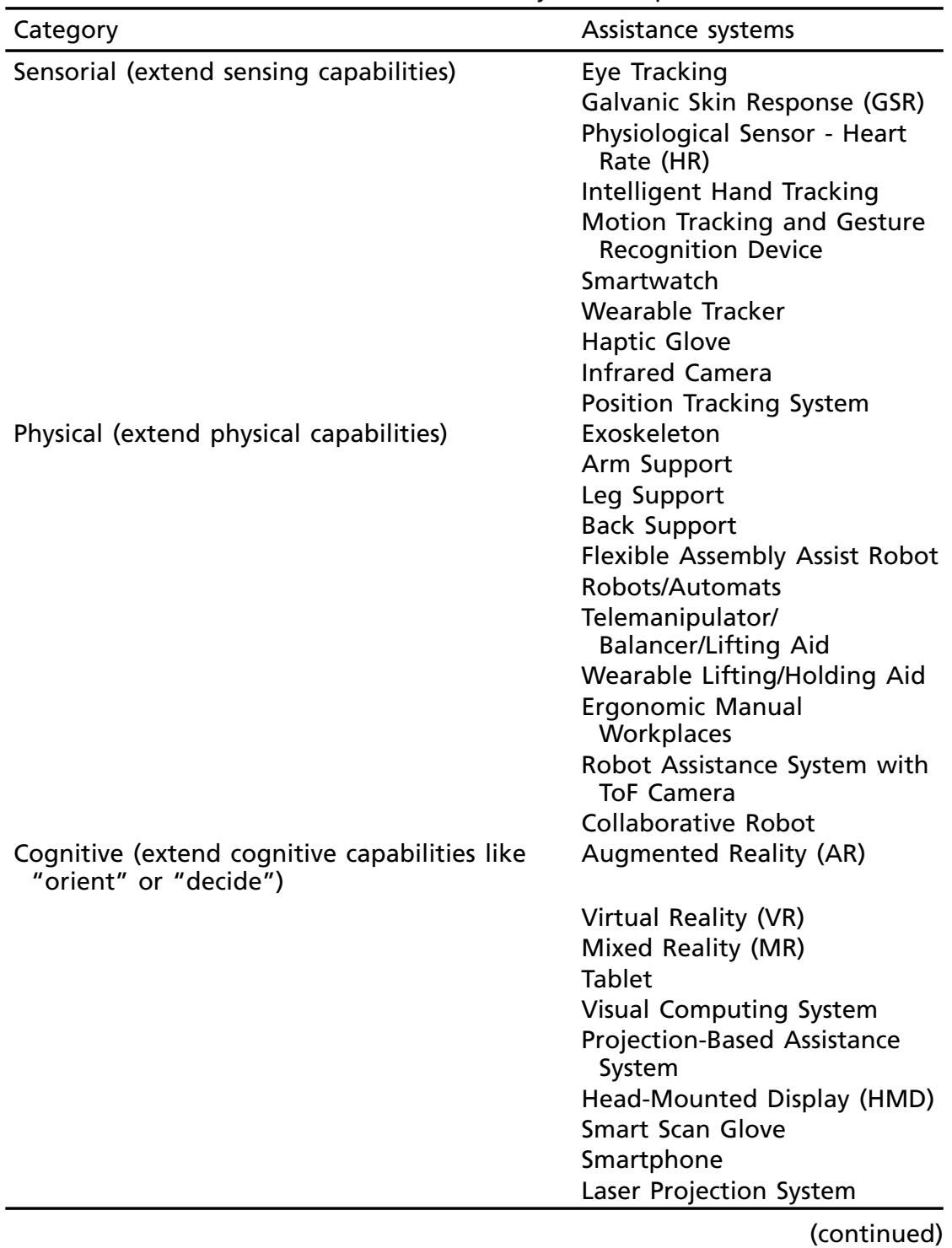


Table 4.2 (continued)

\begin{tabular}{ll}
\hline Category & Assistance systems \\
\hline & Computer Assisted Instructions \\
(CAl) \\
Projector \\
Monitor \\
Pictorial Instruction \\
Voice Control \\
Al-Based Intelligent Personal \\
Assistant \\
\hline
\end{tabular}

\subsubsection{Sensorial Worker Assistance Systems}

Figure 4.7 visualizes and summarizes possible sensorial assistance systems. These systems will be presented in detail in the following.

Eye Tracking: The eye tracking technology refers to the procedure of tracking the absolute Point of Gaze (POG) or the eye movements referring to the user's gaze point in the visual place (Mark et al. 2019c). It is useful in many different applications that range from medical and

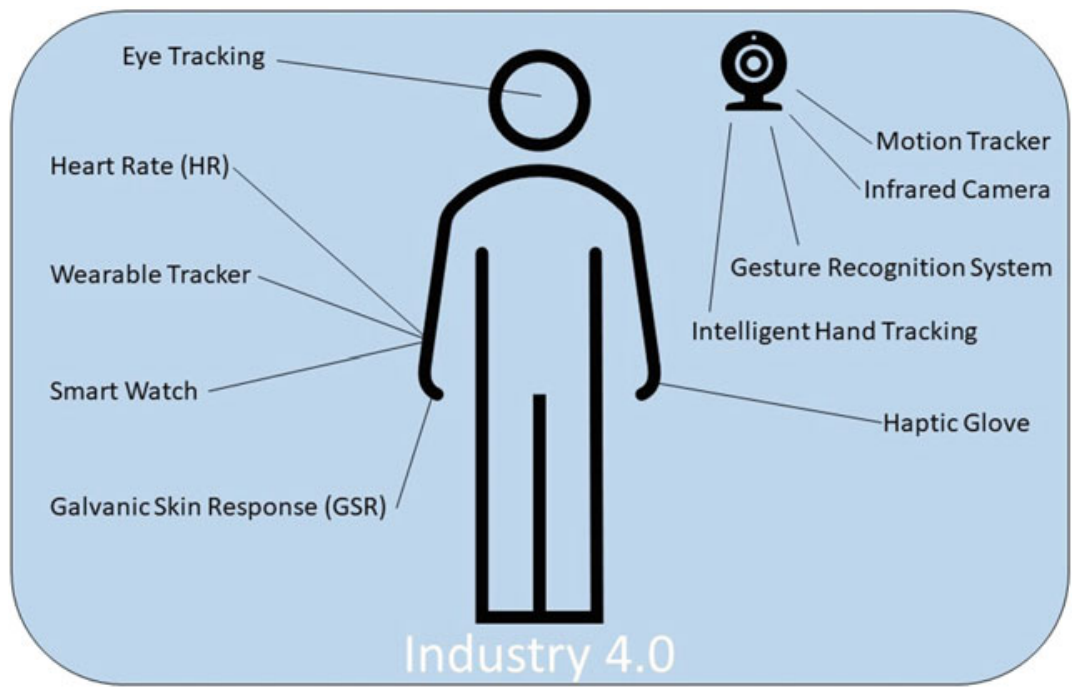

Fig. 4.7 Overview of sensorial worker assistance systems 
psychological research diagnostics to gaze-controlled, interactive applications and usability studies (Majaranta and Bulling 2014). The variety and quantity of publications using eye tracking for their research purpose show that there has been a drastic increase in employing this technology (Reingold 2014). Lusic et al. use eye tracking to draw conclusions on the efficiency of the communication between the actual operator's behaviour, the object to be assembled, and the medium that provides information (Lusic et al. 2016).

Galvanic Skin Response (GSR): Galvanic skin response has been interesting for academic research since the 1900s. The human skin is an organ, which is entirely innervated by the nervous system (Gollan et al. 2018). The GSR is able to analyse and measure the skin's electrodermal activity (EDA) which embodies a reflection of synaptic excitation as the increased conductance of the skin appears in considerable correlations with neuronal actions (Frith and Allen 1983). Therefore, GSR can be used as an indicator of excitation increases with attention during the performance of a task (Kahneman 1973).

Physiological Sensor - Heart Rate (HR): The heart rate which is an example of cardiac functions stands for another fundamental indicator of excitation and arousal and hence of the activation of attention as a direction to changes in the nervous system (Graham 1992). Heart Rate Response (HRR), Heart Rate Variability (HRV), and T-Wave amplitude analysis represent the most expressive indicators of excitation (SuriyaPrakash et al. 2015). The mobile and stationary evaluation of cardiac data can be done both, with medical and customer products through diverse sensors (Gollan et al. 2018).

Intelligent Hand Tracking: An intelligent hand tracking system uses depth cameras in order to track the operator's hands and make him aware in case of wrong actions or errors during the assembly tasks of workers in manual assembly. The system can use different hand tracking algorithms (Büttner et al. 2017).

Motion Tracking and Gesture Recognition Device: Motion tracking or motion capturing is the process of collecting data of people's and object's movements. It is not only used in robotics and in the validation of computer vision, but also in military and entertainment (Noonan et al. 2009; Yamane and Hodgins 2009). A motion sensing and gesture 
recognition device is a technology that includes different hardware, such as infrared projectors, RGB cameras, detectors, and microphones. In literature, it is used for experiments about visual feedback that guides the worker from one assembly step to the next (Funk et al. 2018) and for tracking the assembly process (Gupta et al. 2012).

Smartwatch: A smartwatch is a wearable, small computer that can be worn on the wrist. It usually consists of a touchscreen interface while it is connected to the smartphone app that provides telemetry and management, such as biomonitoring. In industrial literature, it is used to include it in daily production and support the worker with gesture and voice control (Müller et al. 2018b). In addition, it can support step by step instructions of assembly tasks (Aehnelt et al. 2014).

Wearable Tracker: Wearable tracker is the generic term for devices that measure and record stress, Global Positioning System (GPS) location, activity, heart rate, and additional health-related metrics as well as other data, such as biometrics. Nowadays, there is a large selection of such systems. Currently, there are first steps in tracking the complex human brain during tasks, which brings it to the next level. This might take some time to be implemented also in industry but gives an idea of what is already possible (Romero et al. 2016b).

Haptic Glove: A haptic glove can be a kind of glove that makes the operator get in touch with a computer device through haptic technology. It can provide tactile feedback of virtually based objects. When it is activated, it gives feedback about the sensation in terms of the sense of touch of having a virtual object in the hands. In industrial experiments, it is also a glove equipped with diverse sensors to get feedback from real objects in the operator's hand (Otten et al. 2016).

Infrared Camera: Infrared camera, or also thermographic camera, is a device, which can create images by infrared radiations. In literature, operators can express their order and intention by gestures and a system recognizes them via infrared cameras (Oka et al. 2002). An enhanced work desk in production might therefore consist of a desk, projector, infrared camera, and a display (Sugi et al. 2005).

Position Tracking System: Position tracking systems track the position of body parts or systems that are worn by the operator, e.g. a 
head-mounted display. The definition of the precise orientation and position of an object can be done by special markers or trackers (Müller et al. 2018a).

\subsubsection{Physical Worker Assistance Systems}

Figure 4.8 visualizes and summarizes possible physical assistance systems. These systems will be presented in detail in the following.

Exoskeleton: An exoskeleton is a wearable device that is placed on the operator's body and restores, reinforces, or augments the performance. They can be made out of different materials and optionally being equipped with actuators and sensors. Even though they can be seen as universal technical concept, they must be individually adapted to the activity and operator (Weidner et al. 2018).

Arm/Leg/Back Support: There are different types of exoskeleton support systems. According to the individual desire, there also exist arm, leg, back, and overall supports, which are based on soft controls, flexible structures, and textile components (Otten et al. 2016).

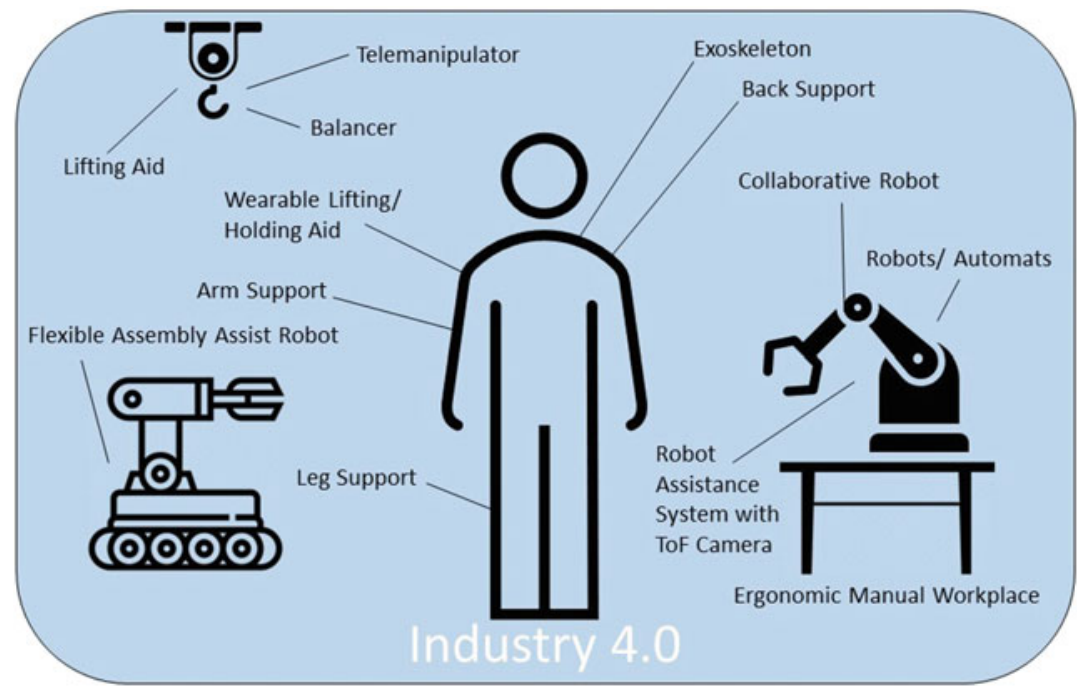

Fig. 4.8 Overview of physical worker assistance systems 
Flexible Assembly Assist Robot: Flexible assembly assist robots can have high potential for assembly and manufacturing. They can improve the cooperation between machine and human (and thus the humanmachine interaction) when considering the safety issues and workplace conditions (Drust et al. 2013).

Human-Robot (machine) Collaboration: Human-machine collaboration (HRC) is the general term for a model in which the operator works together with machines, robots, or other (intelligent) systems and not only using them as an instrument. The goal of such a relationship is to help each other with diverse abilities and to use strengths to fill the other's weaknesses (Rouse 2017).

Robots/Automats: Technical systems for robotic systems and automated solutions for industrial use are free programmable and standardized robots, with parallel and/or serial chains. They can be used together with other robots (or humans), automated machine tools, and alone (Weidner et al. 2013).

Telemanipulator/Balancer/Lifting Aid: Balancers are used to transport an assembly part or workpiece from one workplace to the other. Different from industrial robots, the motion that is given to a balancer is initiated by the operator himself. In dangerous working environments or areas that are not accessible, telemanipulators can be installed (Bruno and Khatib 2008). The operator's commands are communicated by mechanical, electronic, or hydraulic linkages for supervising the robot (Weidner et al. 2013).

Wearable Lifting/Holding Aid: The wearable lifting or holding aid is a passive and portable kinematic module that can be connected to diverse devices. In literature, it is connected to a drill end effector including a device for level compensation with locking possibilities. With the help of the level compensation, it can be ensured that drilling is carried out vertically on the surface. The portable support system can improve ergonomics by transferring the weight of heavy machines, which are normally carried with both arms, over the entire torso. In addition, the levelling device and the locking facility can contribute to improved quality (Weidner et al. 2014).

Ergonomic Manual Workplace: The purpose of ergonomic manual workplaces is that the operator can perform all tasks and gets support by 
pneumatic, electrical, and mechanical tools, such as a screwdriver. The design of an ergonomic workplace seeks to optimize it regarding workflow and organization (Buch et al. 2008) and also to make the design age-differentiated, e.g. with touchscreens (Vetter et al. 2010).

Robot Assistance System with Time-of-flight (ToF) Camera: The technology constitutes the basis for collision-free collaboration between industrial robots and humans. With the help of the real-time depth information, dynamic and static objects are detected which is necessary to install industrial robots as assistants of the operator (Ramer and Franke 2014).

Collaborative Robot: Collaborative robots, also Cobots, are industrial robots that can perform a variety of non-ergonomic and repetitive tasks. They are designed for collaborating directly with the operator while ensuring safety regarding collision and force sensing (Romero et al. 2016b; Gualtieri et al 2019).

\subsubsection{Cognitive Worker Assistance Systems}

Figure 4.9 visualizes and summarizes possible cognitive assistance systems. These systems will be presented in detail in the following.

Augmented Reality (AR): Augmented reality refers to any computeraided expansion of the real world. A use case of the augmented reality technology is supporting operators in search activities by leading their attention towards the important targets (Renner et al. 2018).

Virtual Reality (VR): Virtual reality is a simulated world, which can be totally different from the normal world. This technology can be of great benefit for applications in industry by creating simulations of maintenance tasks, design review, and prototyping. It is used for the training of workers of different equipment, which might reduce problems, risks, and expenses (Wolfartsberger et al. 2018).

Mixed Reality (MR): In mixed reality, the virtual and real world are merged to create new visualizations and environments. The digital and physical objects interact and co-exist in real time. Regarding mixed reality, experiments are conducted to provide virtual support to the worker in form of projected instructions onto a workplace environment. 


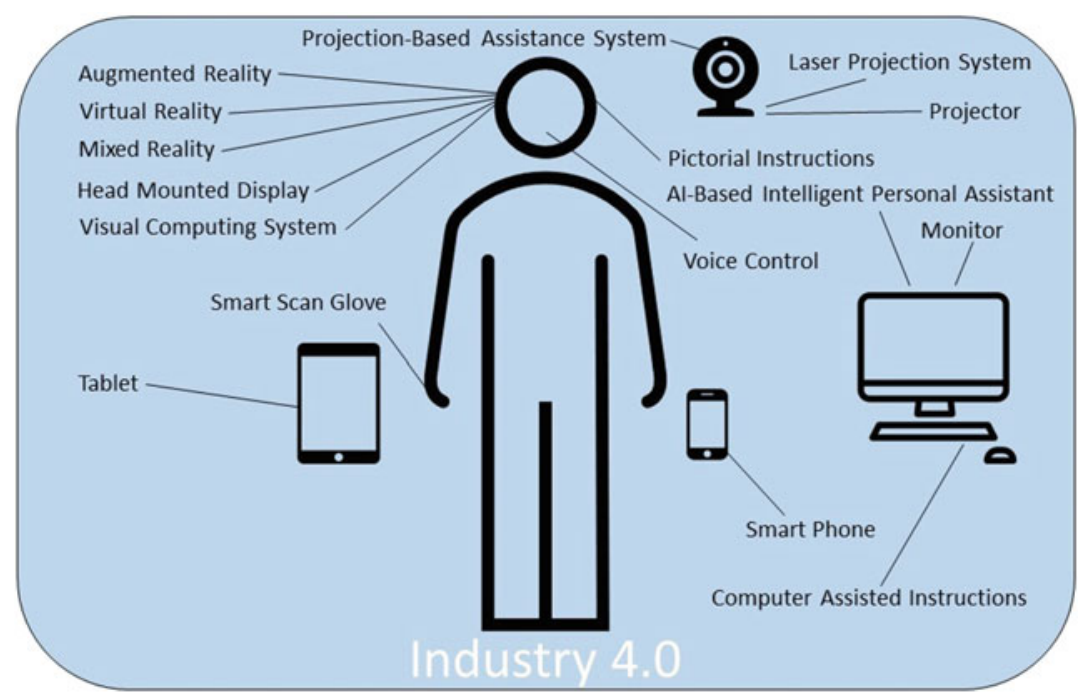

Fig. 4.9 Overview of cognitive worker assistance systems

This could be in form of a mounted projector over the assembly station (Rodriguez et al. 2015).

Tablet: A tablet is a portable, thin, small, and lightweight computer with a touch screen. It has speakers, microphone, and a mechanical or virtual keyboard. In literature, it is used as assistance system at workplaces in assembly lines to show key steps in assembly production (Hallewell Haslwanter and Blazevski 2018).

Visual Computing System: Visual computing is a term for computer science disciplines which deal with 3D models and image information. According to Posada et al. (2015), visual computing is a key technology within Industry 4.0 and contains technologies such as virtual and augmented reality, visual analytics, HMI interfaces, and collaborative robotics interaction (Segura et al. 2018).

Projection-Based Assistance System: A projection-based assistance system is a system, which projects information, e.g. instructions, directly on the operator's field of vision on the workplace (Mark et al. 2020b). They can be flexibly designed in order to be moved to any workplace (Hinrichsen et al. 2018). 
Head-Mounted Display (HMD): A head-mounted display is a device equipped with a display that can be separately worn on the head or be part of a helmet. In most applications mentioned in literature, HMD uses augmented reality, which can be used for training applications and industrial education (Besbes et al. 2012).

Smart Scan Glove: The smart scan glove is a small and light barcode scanner that can be connected to information within the industrial Internet of things. Experiments showed that this type of barcode scanner is better compared to the traditional handheld variant in terms of user acceptance, physical fatigue, and support to humans (Scheuermann et al. 2016).

Smartphone: A smartphone is a device that can be carried by the operator during daily work. It can be connected to the company's internal network. Speaking about Industry 4.0, wearables have great potential although they are still in their infancy. For instance, in literature, it is used to share expert knowledge via push notifications (Scheuermann et al. 2015).

Laser Projection System: Laser projection systems are visual assistance systems that can ensure the quality and efficiency during industrial production and assembly processes. They are used to generate laser lines that can display outlines on objects and surfaces. The shapes can be created from Computer-Aided Design (CAD) files (Müller et al. 2016).

Computer Assisted Instructions (CAI): Computer assisted instructions are usually used in complex tasks that might have a complex set of assembly instructions. The worker has here the possibility to select the appropriate instruction manual online when needed (Tang et al. 2003).

Projector: Projectors are often used in combination with monitors and diverse cameras in order to project instructions or assistance on the workplace of the operator. The price of this technology has been sinking over the last years (Hinrichsen et al. 2018) which makes it more attractive to the companies and researchers.

Monitor: A monitor, similar to the tablet, can be mounted on a workstation and combined with other technologies such as a camera, laser projector, and tracking system (Müller et al. 2018a). 
Pictorial Instructions: Pictorial instructions communicate information in form of drawings whereat text is only used occasionally to clarify the information. Pictures are usually easier to remember and understand. Unlike reading, researchers think that humans learn through exposure and experience how to follow and understand pictorial instructions (Paul 2012). In industrial production, pictorial instructions can be put above boxes with assembly pieces to show how to perform the assembly (Funk et al. 2015).

Voice Control: A voice control system can be combined with collaborative robots in order to work hands-free and enhance the humanmachine interaction. It can raise the efficiency, quality, and automation of the process. The implementation of a voice client enables the interaction between operator and technical system, e.g. projection system, and makes it possible to adapt the voice control specifically to the industrial working environment (Müller et al. 2018b).

AI-Based Intelligent Personal Assistant: An intelligent personal assistant is artificial intelligence or a software agent that can assist the worker in interfacing with databases, computers, machines, and other information systems. A main feature is the voice interaction to the operator, which enhances operational efficiency and productivity (Romero et al. 2016b).

\subsection{Discussion of Risks, Challenges, and Potential}

Already in the year 2014 Creighton writes in the EU Factpack that "Europe is going grey" (Creighton 2014). While at the moment mostly Western and Northern countries in Europe have the oldest populations, according to the EU Factpack this will change by the year 2060 and the countries in the East will have the highest number of inhabitants older than 65 (Creighton 2014). This shows that the ageing of society in Europe and thus also of workers in industrial production will be a major challenge for manufacturing companies in the future. According to Thun et al., this phenomenon was already observable in the year 2007, and the process of aging workforce will accelerate (Thun et al. 2007). 
Assistance systems could therefore counteract this process and support older workers in production. Another aspect is the user-friendliness of assistance systems. An assistance system, to be accepted by employees, must have a practical and supportive effect on the worker and not hinder him/her in any way in daily work. This aspect plays a leading role in this respect. Therefore, when designing and developing these systems, not only the technical aspect and benefits must be considered, but also the relevance and applicability to the worker himself.

One point that is often forgotten is the legal regulation. It has already been mentioned that due to demographic change, a shortage of workers will also occur in manufacturing companies. In this respect, the firms should also be interested in the inclusion of workers with disabilities into the daily work routine. Meanwhile, there is a wide range of different assistance systems that can not only support the worker himself, but also monitor and control the work steps. In literature, scientists are also increasingly concerned about the integration of people with disabilities into everyday working life through suitable assistance systems. Often, however, the practical implementation is difficult due to legal regulations (Mark et al. 2019b).

Due to the increasing complexity of machines and systems within the company, also the human-machine interfaces must be continuously improved. Research is currently developing a way to make HMI safer and more durable with the help of contactless input commands. There are three possible ways of contactless input: (i) input via facial expressions, (ii) input via gestures, and (iii) input via languages (Juschkat 2019). From a research perspective, much progress remains to be made in this area. An example of a HMI discussed, are headsets that measure brain waves (Beigh and Beigh 2018) and could thus in the future directly convert the thoughts of the user into interactions of a machine-e.g. to control robotic arms. Today, this technology is primarily intended for people with robotic prostheses or paraplegics. However, the new technology could also be used for machine control (Juschkat 2019). In addition, technical opportunities, such as machine learning, artificial intelligence, and automation, can play an important role in the future of work (Wang and Siau 2019). 
When looking at the analysed publications, it can be denoted that the area of assistance systems in production is growing due to the increasing number of literature and industrial applications. Many technologies are getting cheaper over the years, which makes them more affordable not only for research centres of universities and large companies but also for research departments of small and medium-sized enterprises (SME).

In conclusion, the following main risks/challenges and potential in the context of worker assistance systems can be pointed out:

\section{Risks/challenges:}

- Demographic change,

- User-friendliness of assistance systems,

- Legal foundations.

\section{Potential:}

- Inclusion of workers with disabilities,

- Advanced human-machine interfaces,

- Affordability of systems.

\subsection{Conclusion}

This chapter examines the opportunity and potential of assistance systems in industrial production to enhance the operator's capabilities and human-machine interaction. The introduction of assistance systems in assembly changes the daily production comprehensively. On the one hand, such systems can give benefit in form of increased operator's capabilities (upgrading) and on the other hand support the operators with mental or physical limitations (compensation). Having in mind that a typical worker of a factory can be classified into different kinds of user groups, with diverse capabilities and limitations, makes it easier to find adequate support. The list of available assistance systems together with an explanation helps the reader to consider each system and estimate their individual potential. The important thing is that these systems provide 
the employee significant form of support and do not cause any additional stress or work. This is the only way to ensure that it can be used in practice sustainably. In addition, the increasing importance of human-machine interface is pointed out. This is mainly due to the high complexity of the systems and machines with which the worker has to work in the company today. In the past, many important technologies have been developed, but most of them only improved the productivity of the company and were generally always company oriented. This is different with assistance systems. They follow the approach of putting the worker in the centre of attention and to improve the company as a whole by equipping the operator with adequate support.

Acknowledgements This project has received funding from the European Union's Horizon 2020 research and innovation programme under the Marie Skłodowska-Curie grant agreement No 734713.

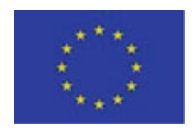

\section{References}

Aehnelt, M., and B. Urban. 2014. Follow-me: Smartwatch assistance on the shop floor. In Lecture Notes in Computer Science (including subseries Lecture Notes in Artificial Intelligence and Lecture Notes in Bioinformatics): 279-287. https://doi.org/10.1007/978-3-319-07293-7_27.

Arnold, D., and K. Furmans. 2019. Materialfluss in Logistiksystemen. Berlin: Springer. https://doi.org/10.1007/978-3-642-01405-5.

Bächler, A., L. Bächler, S. Autenrieth, H. Behrendt, M. Funk, G. Krüll, T. Hörz, T. Heidenreich, C. Misselhorn, and A. Schmidt. 2018. Systeme zur Assistenz und Effizienzsteigerung in manuellenProduktionsprozessen der Industrie auf Basis von Projektion und Tiefendatenerkennung. In: Wischmann S., and E. Hartmann (eds) Zukunft der Arbeit - EinepraxisnaheBetrachtung. Springer Vieweg, Berlin, Heidelberg. https://doi.org/10. 1007/978-3-662-49266-6_3. 
Beigh, N.T., and F.T. Beigh. 2018. A review on brain wave signal appliance control. International Journal for Research in Applied Science and Engineering Technology 6. https://doi.org/10.22214/ijraset.2018.4403.

Besbes, B., S.N. Collette, M. Tamaazousti, S. Bourgeois, and V. Gay-Bellile. 2012. An interactive augmented reality system: A prototype for industrial maintenance training applications. In IEEE International Symposium on Mixed and Augmented Reality (ISMAR): 269-270. https://doi.org/10. 1109/ISMAR.2012.6402568.

Böhle, F. 2005. Erfahrungswissen - die verborgenenSeitenprofessionellenHandelns. EineHerausforderungfür die beruflicheBildung. Bonn: Fachtagung des BundesinstitutsfürBerufsbildung.

Bruno, S., and O. Khatib. 2008. Springer handbook of robotics. Berlin: Business Media.

Buch, M., J. Weichel, and E. Frieling. 2008. Analyse und Gestaltung von Montagearbeitsplätzen in der Automobilindustrie - EinBeitrag zur GenerierungaltersgerechterArbeitssysteme. GFA (Hrsg.) Produkt- und Produktions-Ergonomie-AufgabefürEntwickler und Planer. GFA Press: 411-414.

Büttner, S., O. Sand, and C. Röcker. 2017. Exploring design opportunities for intelligent worker assistance: a new approach using projetion-based AR and a novel hand-tracking algorithm. In Lecture Notes in Computer Science (including subseries Lecture Notes in Artificial Intelligence and Lecture Notes in Bioinformatics): 33-45. https://doi.org/10.1007/978-3-319-569 97-0_3.

Capability (General) business dictionary. 2016. https://www.businessdiction ary.com.

Creighton, H. 2014. Europe's ageing demography. ILC-UK2014 EU Factpack. www.ilcuk.org.uk. Published in November 2014. Registered Charity Number: 1080496.

Deutscher Bundestag. 2016. WissenschaftlicheDienste: AktuellerBegrifflndustrie 4.0. Available online: https://www.bundestag.de/resource/blob/474528/ cae2bfac57f1bf797c8a6e13394b5e70/industrie-4-0-data.pdf. Nr. 23/16 (article from September 26, 2016). Accessed on June 22, 2020.

Drust, M., T. Dietz, A. Pott, and A. Verl. 2013. Production assistants: The rob@work family. In 44th International Symposium on Robotics (ISR): 6695746. https://doi.org/10.1109/ISR.2013.6695746.

Frith, C.D., and H.A. Allen. 1983. The skin conductance orienting response as an index of attention. Biological Psychology 17 (1): 27-39. https://doi.org/ 10.1016/0301-0511(83)90064-9. 
Funk, M., L. Lischke, S. Mayer, A.S. Shirazi, and A. Schmidt. 2018. Teach me how! Interactive assembly instructions using demonstration and insitu projection. Cognitive Science and Technology 49-73. https://doi.org/10. 1007/978-981-10-6404-3_4.

Funk, M., S. Mayer, and A. Schmidt. 2015. Using in-situ projection to support cognitively impaired workers at the workplace. In Proceedings of the 17th International ACMSIGACCESS Conference on Computers and Accessibility: 185-192. https://doi.org/10.1145/2700648.2809853.

Gollan, B., M. Haslgruebler, A. Ferscha, and J. Heftberger. 2018. Making sense: Experiences with multi-sensor fusion in industrial assistance systems. In Proceedings of the 5th International Conference on Physiological Computing Systems: 64-74. https://doi.org/10.5220/0007227600640074.

Gorecky, D., M. Schmitt, M. Loskyll, and D. Zuhlke. 2014. Human-machineinteraction in the industry 4.0 era. In Proceedings of the 12th IEEE International Conference on Industrial Informatics: 289-294. https://doi. org/10.1109/INDIN.2014.6945523.

Graham, F.K. 1992. Attention: The heartbeat, the blink, and the brain. Attention and information processing in infants and adults: Perspectives from human and animal research. In B.A. Campbell, H. Hayne, and R. Richardson (Eds.), Attention and information processing in infants and adults: Perspectives from human and animal research: 3-29.

Gualtieri, L., E. Rauch, R. Vidoni, and D.T. Matt. 2019. An evaluation methodology for the conversion of manual assembly systems into humanrobot collaborative workcells. Procedia Manufacturing 38: 358-366. https:// doi.org/10.1016/j.promfg.2020.01.046.

Gualtieri, L., I. Palomba, F.A. Merati, E. Rauch, and R. Vidoni. 2020. Design of human-centered collaborative assembly workstations for the improvement of operators' physical ergonomics and production efficiency: A case study. Sustainability 12 (9): 3606. https://doi.org/10.3390/su12093606.

Gupta, A., D. Fox, B. Curless, and M. Cohan. 2012. DuploTrack: A realtime system for authoring and guiding duplo block assembly. In Proceedings of the 25th Annual ACM Symposium on User Interface Software and Technology: 389-401. https://doi.org/10.1145/2380116.2380167.

Hallewell Haslwanter, J.D., and B. Blazevski. 2018. Experiences with an assistive system for manual assembly. ACM International Conference Proceeding Series 46-49. https://doi.org/10.1145/3197768.3203173. 
Hinrichsen, S., D. Riediger, and A. Unrau. 2016. Assistance systems in manual assembly. Production Engineering and Management. In Proceedings 6th International Conference. Publication Series in Direct Digital Manufacturing, eds. F. J. Villmer, E. Padoano: Volume: 6

Hinrichsen, S., D. Riediger, and A. Unrau. 2018. Development of a projectionbased assistance system for maintaining injection molding tools. IEEE International Conference on Industrial Engineering and Engineering Management 1571-1575. https://doi.org/10.1109/IEEM.2017.8290157.

Juschkat, K. 2019. ElektrotechnikAutomatisierung. Was it human machine interface? Definition, Geschichte \& Beispiele. Available online: https:// www.elektrotechnik.vogel.de/was-ist-human-machine-interface-definitiongeschichte-beispiele-a-718202/ (article from April 10, 2019). Accessed on June 22, 2020.

Kahneman, D. 1973. Attention and effort, vol. 1063. NJ: Prentice-Hall Enlegwood Cliffs.

Korn, O. 2012. Industrial playgrounds: How gamification helps to enrich work for elderly or impaired persons in production. In Proceedings of the 2012 ACMSIGCHI Symposium on Engineering Interactive Computing Systems: 313-316. https://doi.org/10.1145/2305484.2305539.

Layne, E. 2019. Small business: How are pictographs used in a workplace? Available online: https://smallbusiness.chron.com/pictographs-used-workpl ace-38856.html. Accessed on 15 September 2019.

Lusic, M., C. Fischer, K.S. Braz, M. Alam, R. Hornfeck, and J. Franke. 2016. Static versus dynamic provision of worker information in manual assembly: A comparative study using eye tracking to investigate the impact on productivity and added value based on industrial case examples. ProcediaCIRP 57: 504-509. https://doi.org/10.1016/j.procir.2016.11.087.

Majaranta, P., and A. Bulling. 2014. Chapter 3: Eye tracking and eye-based human-computer interaction. In Advances in Physiological Computing. Human-Computer Interaction Series (S.H. Fairclough, K. Gilleade). Springer-Verlag London. https://doi.org/10.1007/978-1-4471-6392-3_3.

Mark, B.M., L. Gualtieri, E. Rauch, R. Rojas, D. Buakum, and D.T. Matt. 2019a. Analysis of user groups for assistance systems in production 4.0. In International Conference on Industrial Engineering and Engineering Management (IEEM). https://doi.org/10.1109/IEEM44572.2019. 8978907.

Mark, B.G., S. Hofmayer, E. Rauch, and D.T. Matt. 2019b. Inclusion of workers with disabilities in production 4.0: Legal foundations in Europe and 
potentials through worker assistance systems. Sustainability (Switzerland) 11(21): 5978. https://doi.org/10.3390/su11215978.

Mark, B. G., E. Rauch, Y. Borgianni, and D.T. Matt. 2019c. Eye tracking in der produktion 4.0: Eye tracking alsnützliche Technologie zur Optimierung der Produktionsprozesse im Zeitalter von Industrie 4.0. ZWF Zeitschrift fürwirtschaftlichenFabrikbetrieb, 114(1-2): 72-75. https://doi. org/10.3139/104.112032.

Mark, B.G., L. Gualtieri, M. De Marchi, E. Rauch, and D.T. Matt. 2020a. Function-based mapping of industrial assistance systems to user groups in production. (Accepted at CIRPe 2020 - 8th CIRP Global Web Conference - Flexible Mass Customisation).

Mark, B. G., E. Rauch, and D.T. Matt. 2020b. Study of the impact of projection-based assistance systems for improving the learning curve in assembly processes. In ProcediaCIRP, 88: 98-103. https://doi.org/10.1016/ j.procir.2020.05.018.

Matt, D.T. 2007. Reducing the structural complexity of growing organizational systems by means of axiomatic designed networks of core competence cells. Journal of Manufacturing Systems, 26(3-4): 178-187. https://doi.org/10. 1016/j.jmsy.2008.02.001.

Matt, D.T. 2009. Design of lean manufacturing support systems in make-toorder production. Key Engineering Materials 410: 151-158. https://doi.org/ 10.4028/www.scientific.net/KEM.410-411.151.

Müller, R., M. Vette, M. Scholer, and J. Ball. 2016. Assembly assistance and position data feedback by means of projection lasers. SAE Technical Papers.

Mueller, R., M. Vette-Steinkamp, L. Hoerauf, C. Speicher, and A. Bashir. 2018. Intelligent and flexible worker assistance systems assembly assistance platform for planning assisted assembly and rework as well as execution of a worker-centered assistance. VISIGRAPP 2018: 77-85. https://doi.org/10. 5220/0006613900770085.

Müller, R., M. Vette-Steinkamp, L. Hörauf, C. Speicher, and A. Bashir. 2018a. Worker centered cognitive assistance for dynamically created repairing jobs in rework area. ProcediaCIRP 72: 141-146. https://doi.org/10.1016/j.pro cir.2018.03.137.

Müller, R., R. Müller-Polyzou, L. Hörauf, A. Bashir, M. Karkowski, D. Vesper, and S. Gärtner. 2018b. Intuitive control of laser based assembly assistance [Intuitive BedienunglaserbasierterMontageassistenz]. ZWF Zeitschrift fuerWirtschaftlichenFabrikbetrieb, 113(6): 363-368. https://doi.org/ https:// doi.org/10.3139/104.111922. 
Noonan, D., P. Mountney, D. Elson, A. Darzi, and G.Z. Yang. 2009. A stereoscopic fibroscope for camera motion and 3D depth recovery during minimally invasive surgery. ProcediaICRA 2009: 4463-4468. https://doi. org/10.1109/ROBOT.2009.5152698.

Oka, K., Y. Sato, and H. Koike. 2002. Real-time fingertip tracking and gesture recognition. In IEEE Computer Graphics and Applications, 22(6): 64-71. https://doi.org/10.1109/MCG.2002.1046630.

Otten, B., P. Stelzer, R. Weidner, A. Argubi-Wollesen, and J.P. Wulfsberg. 2016. A novel concept for wearable, modular and soft support systems used in industrial environments. Proceedings of the Annual Hawaii International Conference on System Sciences 542-550. https://doi.org/10.1109/HICSS.201 6.74.

Papcun, P., E. Kajati, and J. Koziorek. 2018. Human machine interface in concept of industry 4.0. In World Symposium on Digital Intelligence for Systems and Machines (DISA). https://doi.org/10.1109/DISA.2018.849 0603.

Paul, Y., Techwhirl. Pictorial instructions-What are they good for? Available online: https://techwhirl.com/pictorial-instructions-what-good/ (Article form December 5, 2012). Accessed on June 30, 2020.

Posada, J., C. Toro, I. Barandiaran, D. Oyarzun, D. Stricker, R. De Amicis, E.B. Pinto, P. Eisert, J. Dollner, and I. Vallarino. 2015. Visual computing as a key enabling technology for industries 4.0 and industrial internet. In IEEE Computer Graphics and Applications 35 (2): 26-40. https://doi.org/ 10.1109/MCG.2015.45.

Ramer, C., and J. Franke. 2014. Work space surveillance of a robot assistance system using a ToF camera. Advanced Materials Research 907: 291-298. https://doi.org/10.4028/www.scientific.net/AMR.907.291.

Rauch, E., P. Dallasega, and D.T. Matt. 2017. Critical factors for introducing lean product development to small and medium sized enterprises in Italy. ProcediaCIRP 60: 362-367. https://doi.org/10.1016/j.procir.2017.01.031.

Reingold, E. 2014. Eye tracking research and technology: Towards objective measurement of data quality. Visual Cognition 22 (3): 635-652. https://doi. org/10.1080/13506285.2013.876481.

Reinhart, G., and M. Zäh. 2014. Assistenzsysteme in Der Produktion. WtWerkstattstechnik-Online 104 (9): 516.

Renner, P., J. Blattgerste, and T. Pfeiffer. 2018. A path-based attention guiding technique for assembly environments with target occlusions. In IEEE Conference on Virtual Reality and 3D User Interfaces (VR) - Proceedings, 8446127: 671-672. https://doi.org/10.1109/VR.2018.8446127. 
Rodriguez, L., F. Quint, D. Gorecky, D. Romero, and H.R. Siller. 2015. Developing a mixed reality assistance system based on projection mapping technology for manual operations at assembly workstations. Procedia Computer Science 75: 327-333. https://doi.org/10.1016/j.procs.2015.12.254.

Romero, D., P. Bernus, O. Noran, J. Stahre, and A. Fast-Berglund. 2016a. The operator 4.0: Human cyber-physical systems \& adaptive automation towards human-automation symbiosis work systems. In IFIP International Conference on Advances in Production Management Systems: 677-686. https:// doi.org/10.1007/978-3-319-51133-7_80.

Romero, D., J. Stahre, T. Wüst, O. Noran, P. Bernus, A. Fast-Berglund, and D. Gorecky. 2016b. Towards an operator 4.0 typology: A humancentric perspective on the fourth industrial revolution technologies. In 46th International Conferences on Computers and Industrial Engineering: 1-11.

Rothenberger, R. IT Production online - Das Industrie 4.0MagazinfürerfolgreicheProduktion. DigitaleAssistenzsysteme in der Produktion. Available online: https://www.it-production.com/fertigung snahe-it/unterstuetzung-fuer-werker/\#:- :text=Digitale\%20Assistenzsyst eme $\% 20$ sind $\% 20$ ein $\% 20$ wichtiger,Produktivit\%C3\%A4t\%20und\%20W ettbewerbsf\%C3\%A4higkeit\%20eines\%20Unternehmens. (Article from January 23, 2020). Accessed on June 23, 2020.

Rouse, M., Definition: Machine-human collaboration. Available online: https://whatis.techtarget.com /definition/machine-human-collaboration\#. (Article from January, 2017). Accessed on June 29, 2020.

Scheuermann, C., B. Bruegge, J. Folmer, and S. Verclas. 2015. Incident localization and assistance system: A case study of a cyber-physical human system. IEEE/CIC International Conference on Communications in China Workshops, CIC/ICCC 57-61. https://doi.org/10.1109/ICCChinaW.2015. 7961580.

Scheuermann, C., M. Strobel, B. Bruegge, and S. Verclas. 2016. Increasing the support to humans in factory environments using a smart glove: An evaluation. In IEEE Conferences on Ubiquitous Intelligence \& Computing, Advanced and Trusted Computing, Scalable Computing and Communications, Cloud and Big Data Computing, Internet of People, and Smart World Congress: 847-854. https://doi.org/ https://doi.org/10.1109/UIC-ATC-Sca lCom-CBDCom-IoP-SmartWorld.2016.0134.

Segura, Á., H.V. Diez, I. Barandiaran, A. Arbelaiz, H. Álvarez, B. Simoes, J. Posada, A. García-Alonso, and R. Ugarte. 2018. Visual computing technologies to support the Operator 4.0. In Computers and Industrial Engineering. https://doi.org/10.1016/j.cie.2018.11.060. 
Sugi, M., M. Nikaido, Y. Tamura, J. Ota, T. Arai, K. Kotani, K. Takamasu, S. Shin, H. Suzuki, and Y. Sato. 2005. Motion control of self-moving trays for human supporting production cell "attentive workbench". Proceedings - IEEE International Conference on Robotics and Automation 4080-4085. https://doi.org/10.1109/ROBOT.2005.1570746.

Suriya-Prakash, M., G. John-Preetham, and R. Sharma. 2015. Is heart rate variability related to cognitive performance in visuospatial working memory. Psychology. https://doi.org/10.7287/PEERJ.PREPRINTS.1377V1.

Tang, A., C. Owen, F. Biocca, and W. Mou. 2003. Comparative effectiveness of augmented reality in object assembly. Conference on Human Factors in Computing Systems 73-80. https://doi.org/10.1145/642611.642626.

Thun, J.H., A. Größler, and S. Miczka. 2007. The impact of the demographic transition on manufacturing: Effects of an ageing workforce in German industrial firms. Journal of Manufacturing Technology Management. https:// doi.org/10.1108/17410380710828299.

Vetter, S., J. Bützler, and N. Jochems. 2010. Ergonomic workplace design for the elderly: Empirical analysis and biomechanical simulation of information input on large touch screens. In W. Karwowski, G. Salvendy (Hrsg.) Conference proceedings of the 3rd international conference on applied human factors and ergonomics (AHFE): 1-8. ISBN: 0-9796435-4-6, 978-0-9796435-4-5.

Wang, W., and K. Siau. 2019. Artificial intelligence, machine learning, automation, robotics, future of work and future of humanity: A review and research agenda. Journal of Database Management (JDM). https://doi.org/10.4018/ JDM.2019010104.

Weidner, R., N. Kong, and J.P. Wulfsberg. 2013. Human hybrid robot: A new concept for supporting manual assembly tasks. Production Engineering 7 (6): 675-684. https://doi.org/10.1007/s11740-013-0487-x.

Weidner, R., T. Redlich, and J.P. Wulfsberg. 2014. Passive and active support systems for production processes [Passive und aktiveUnterstützungssystemefür die Produktion]. WTWerkstattstechnik 104 (9): 561-566.

Weidner, R., T. Redlich, and J.P. Wulfsberg. 2015. TechnischeUnterstützungssysteme. Berlin: Springer.

Weidner, R., B. Otten, A. Argubi-Wollesen, and Z. Yao. 2018. Support technologies for industrial production. Biosystems and Biorobotics 23: 149-156. https://doi.org/10.1007/978-3-030-01836-8_14.

Wolfartsberger, J., R. Lindorfer, J.D. Hallewell Haslwanter, M. Jungwirth, R. Froschauer, and D. Wahlmüller. 2018. Industrial perspectives on assistive 
systems for manual assembly tasks. ACM International Conference Proceeding Series 289-291. https://doi.org/10.1145/3197768.3201552.

Yamane, K., and J.K. Hodgins. 2009. Simultaneous tracking and balancing of humanoid robots for imitating human motion capture data. In Intelligent Robots and Systems (IROS) IEEE/RSJ International Conference on Intelligent robots and systems: 2510-2517. https://doi.org/10.1109/IROS.2009. 5354750.

Zittlau, K. 2015a. HaufeArbeitsschutz Office. Assistenzsyteme in der Arbeitswelt 4.0 / 1.1 KognitivunterstützendeAssistanzsysteme. Available online: https://www.haufe.de/arbeitsschutz/arbeitsschutz-office/assistenzsys teme-in-der-arbeitswelt-40-11-kognitiv-unterstuetzende-assistenzsysteme_i desk_PI957_HI11359363.html. Accessed on June 22, 2020.

Zittlau, K. 2015b. HaufeArbeitsschutz Office. Assistenzsyteme in der Arbeitswelt 4.0 / 1.2 PhysischunterstützendeAssistenzsysteme. Available online: https://www.haufe.de/arbeitsschutz/arbeitsschutz-office/assistenzsys teme-in-der-arbeitswelt-40-12-physisch-unterstuetzende-assistenzsysteme_i desk_PI957_HI11359364.html. Accessed on June 22, 2020.

Open Access This chapter is licensed under the terms of the Creative Commons Attribution 4.0 International License (http://creativecommons.org/ licenses/by/4.0/), which permits use, sharing, adaptation, distribution and reproduction in any medium or format, as long as you give appropriate credit to the original author(s) and the source, provide a link to the Creative Commons license and indicate if changes were made.

The images or other third party material in this chapter are included in the chapter's Creative Commons license, unless indicated otherwise in a credit line to the material. If material is not included in the chapter's Creative Commons license and your intended use is not permitted by statutory regulation or exceeds the permitted use, you will need to obtain permission directly from the copyright holder.

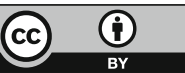

